\title{
Configuraciones metafóricas en la narrativa argentina sobre memorias de dictadura
}

Metaphoric configurations in Argentinian Narrative about Dictatorship Memories

\section{ROSSANA NOFAL}

UNIVERSIDAD NACIONAL DE TUCUMÁN/ CONICET . rossananofal@yahoo.com.ar Es Investigadora Adjunta del CONICET y Profesora Adjunta de Literatura Latinoamericana en la Universidad Nacional de Tucumán. Ha publicado el libro La escritura testimonial en América latina. Imaginarios revolucionarios del sur (2002). Autora de diversos artículos como "Literatura y testimonio" en Miguel Dalmaroni, La investigación literaria. Problemas iniciales de una práctica (2009); "Desaparecidos, militantes y soldados: de la literatura testimonial a los partes de guerra" en Emilio Crenzel, Los desaparecidos en la Argentina. Memorias, representaciones e ideas (2010) y "Las nuevas configuraciones del relato testimonial. La escritura de Federico Lorenz: de ballenas, locura y los mares del sur” en Anna Forné Stategies autoficcionelles/ Estrategias autoficcionales (2014).

RECIBIDO: 10 DE DICIEMBRE DE 2015

DOI: $10.7203 /$ KAM.6.7603

ACEPTADO: 20 DE DICIEMBRE DE 2015

ISSN: 2340-1869

Resumen: El presente ensayo organiza los principales presupuestos poéticos del género testimonial en clave de lectura de las nuevas configuraciones metafóricas que organizan las memorias en conflicto: las batallas y sus vestuarios, los poetas y los traperos. El trabajo historiza los primeros desarrollos conceptuales del género y sus protocolos de veracidad anclados en el familismo de los primeros relatos testimoniales muy próximos al discurso jurídico. Asimismo expone las rupturas retóricas que imprimen en el género las nuevas poéticas testimoniales organizadas en Argentina por las narrativas de Laura Alcoba y Federico Lorenz, principalmente. La lectura de las obras de ambos autores permite profundizar las exploraciones sobre los conceptos de cuento (Ludmer, 1977; Nofal, 2010) y guardarropía revolucionaria (Rama, 1985; Nofal, 2014 b) inscriptos en las escrituras testimoniales más recientes.

Palabras Clave: Narrativa testimonial, Configuraciones metafóricas, memorias en conflicto, guerra.
Resumen: The following article lays out the main poetic postulates of the testimonial narrative through the reading of the new metaphoric configurations that organise memories in conflict: the tales of war and the heroic accounts of revolutionary defeats. It historicises the first conceptual developments of the genre and its veracity protocols anchored in the familism of the first testimonial accounts, very close to the legal discourse. Likewise, it exposes the rhetoric breakdowns imprinted on the genre by the new testimonial poetics, as organised in Argentina mainly by the narratives of Laura Alcoba and Federico Lorenz. The reading of the work of both authors allows us to further explorations on the concepts of «short-story» (Ludmer, 1977; Nofal, 2010) and «revolutionary wardrobe» inscribed in the most recent testimonial writings.

Palabras Clave: Testimonial narrative; New metaphoric configurations; Memories in conflict; War. 


\section{Introducción: la verdad de la experiencia y la relación entre memorias y testimonios}

El presente ensayo organiza los principales presupuestos poéticos del género testimonial. Historiza los primeros desarrollos conceptuales del género y sus protocolos de veracidad anclados en el familismo de los primeros relatos. Asimismo expone las rupturas retóricas que imprimen en el género las nuevas poéticas testimoniales organizadas en Argentina por las narrativas de Laura Alcoba y Federico Lorenz, principalmente.

La lectura de las obras de ambos autores permite profundizar las exploraciones sobre los conceptos de "cuento" (Ludmer, 1977; Nofal, 2010) y "guardarropía revolucionaria" (Rama, 1985; Nofal, 2014 b) inscriptos en las escrituras testimoniales más recientes. El desarrollo analítico sobre la escritura testimonial en términos de cuentos de guerra permite exploraciones más allá de las delimitaciones geográficas, dado sus condiciones de partículas inscriptas en relatos mayores. Inicialmente tomo el concepto de Josefina Ludmer (1977:148) que define cuento en términos de matrices productoras que pueden ser diversas e indefinidas. Se trata de relatos de carácter fragmentario, que se reiteran como partes de historias mayores. Involucran saberes y anécdotas que se transmiten oralmente.

Sumo a la operatividad del concepto la complejidad de la escucha de los relatos de memoria y la necesidad de un lector extraño (Nofal 2009: 148) para quien la experiencia de lo traumático es una experiencia narrativa. Los relatos de un pasado militante, los relatos heroicos sobre el pasado en términos de una "literatura de las virtudes" (Nofal, 2009, 2010) adquieren en el presente esta forma de cuentos en tanto cada protagonista inscribe su propia subjetividad en el relato. Es cada vez más distante, temporalmente, el relato del testigo y más compleja la construcción asertiva del "yo estuve allił", estructura canónica de legitimación de los relatos testimoniales. En el corpus constituido por escritos autobiográficos, la principal desviación de tiene que ver con la supervivencia física del testigo, situación que radicaliza al extremo el problema de la veracidad, inherente a cualquier investigación en términos de memoria. Pero la lejanía en el tiempo y las distintas temporalidades superpuestas en las narrativas sobre la militancia armada, permiten la consolidación de narrativas pautadas por una sensación de "ajenidad" determinada por el uso de un ropaje extraño. La ropa de los revolucionarios, organizada con la poética del vestuario en el teatro, organiza un archivo de metáforas que consolidan la distancia y exponen la construcción que opera en el relato testimonial más allá del mandato inicial del relato de la verdad literal de los hechos.

La literatura testimonial argentina más reciente avanza en términos de una posición más ajena al "familismo" de los primeros relatos testimoniales (Jelin, 2006) y buscan modular sus propios cuentos de guerra. La necesidad de explorar una verdad compromete a un nosotros poco conocido, incluso de 
nuevas generaciones. Los primeros protagonistas fueron compañeros, compañeras, hermanos, hermanas, madres y padres quienes ocuparon los lugares del testigo de los hechos a la vez que asumieron el mandato de hablar por los muertos, su palabra estuvo legitimada por la pertenencia a un nosotros inclusivo. En las narrativas más recientes, el testigo se convierte en personaje y encuentra otras legitimidades para enunciar su relato; si bien no puede desvincularse de los protocolos iniciales su expresividad no está potenciada por la cercanía a las víctimas sino, tal vez, por el campo intelectual que lo autoriza.

La historia de una vida se convierte en una historia contada; los cuentos permiten encadenar la identidad de lo semejante en las variaciones de cada experiencia personal. Sumo a la configuración teórica del ensayo los postulados de Elizabeth Jelin en torno al concepto de los trabajos de la memoria en tanto la construcción de narrativas sobre los procesos sociales ancladas en la historicidad y con un eje en el conflicto y la disputa; los modos del ocultamiento son constitutivos de estas memorias sobre el pasado. Por otro lado, la categoría inicial del "emprendedor de memoria” acuñada por Jelin en el año 2002 para definir a los activistas políticos vinculados a las luchas por las memorias, se reemplaza, en los nuevos formatos, por la figura del contador de cuentos. El "cuentero" es el encargado de contra las historias de la violencia política, transmitirlas entre las distintas generaciones. Sobre el trabajo inicial del trauma y sus duelos suma los mandatos de la elaboración del pasado reciente en clave de complejidad y metáforas.

La tradición ha puesto en este arquetipo del cuentero la inventiva y la seducción de la ceremonia del cuento y el inevitable enlace que une varios cuentos entre sí. Reconocer la naturaleza narrativa y ficcional de las historias no implica abandonar la voluntad de verdad. La dialéctica de la concordancia y de la discordancia posibilita, en términos de Paul Ricoeur (1999: 224), identificar en la escritura testimonial argentina más reciente un giro desde la centralidad de la trama a la identidad del personaje. Este desplazamiento que se sucede en la poética permite imaginar un sentido y una identidad referida, principalmente en el acto de la escritura. Los silencios, las memorias subterráneas, los huecos en la memoria colectiva necesitan de la construcción de una "evidencia imaginativa" para inscribir la subjetividad y crear los cuentos del género: donde cada sapo canta su canción. Para que exista un cuento tiene que haber antes algo que relatar y antes quizás, la disposición de "dejarse engañar"; nada de lo que se relata puede ser efectivamente real; la narración expone, de manera inequívoca, las variaciones del lenguaje y el estilo. La proximidad que existe entre las nociones de configuración y de figura posibilita llevar a cabo un análisis de los personajes heroicos "considerado como figura del sí mismo" (Ricoeur, 1999: 220). 
Rossana Nofal. Configuraciones metafóricas en la narrativa...

\section{Constelaciones y sentidos: el compromiso subjetivo del narrador}

Lo que ha sido se junta en un destello con el ahora para formar una constelación

Walter Benjamin

Escribir una historia significa ubicar un acontecimiento en un contexto relacionándolo con una totalidad imaginable. La dictadura argentina es una historia contada una y otra vez con por los escritores con el oficio de narrar, infinitamente una tumba sin nombre, acaso, inimaginable. El género testimonial ha contado las historias de las desapariciones en nuestro país. Un género con marcas particulares, inicialmente entendido como un relato verosímil, con las marcas de la oralidad inicial de la entrevista y las formas del realismo decimonónico. Desde su punto inicial, la escritura testimonial disputa una categoría artística, en el espacio mismo de la literatura; escritura sobre el pasado que junta destellos de verdad diseminados en distintos relatos sobre el presente. Los testimonios y sus configuraciones metafóricas organizan constelaciones de sentido sobre el pasado y sus disputas por las memorias.

\section{Historizar las memorias: Antecedentes de un género en construcción}

Inicialmente el testimonio se definió como un género que rechazó las leyes de la representación artística y se imaginó fiel reproductor de lo real, más próximo a la veracidad de crónica periodística que a los modos retóricos del relato literario. Se opuso a los modos de producción de la ficción, privilegiando el contenido por sobre la forma y polemizando con la idea de construcción del testimonio. Ante las definiciones estéticas, reivindicó la tradición de una literatura militante emparentada con la tradición política del realismo socialista.

La escritura como una acción revolucionaria y la construcción del discurso heroico son dos de las marcas identitarias más importantes en la constitución inicial del género. Un testimonio inaugural en Argentina es, indudablemente, el libro Recuerdo de la muerte de Miguel Bonasso publicada por la editorial por Planeta en el año 1994. El autor reconstruye testimonios con voz propia a partir de los relatos de los sobrevivientes de dos Campos Clandestinos de Detención: la Escuela de Mecánica de la Armada en Buenos Aires y Funes en Córdoba. Las tramas narrativas sobre las acciones colectivas hiperbolizan las acciones individuales de los protagonistas de los hechos construidos discursivamente como héroes o como traidores.

Los testimonios de los sobrevivientes borran los fantasmas de la traición y la delación bajo tortura y organizan un imaginario heroico de virtudes políticas inscripto una narrativa sin fisuras (Nofal, 2009: 142). Siguiendo la lógica de Williams en Marxismo y Literatura podemos decir que todo relato se crea a

partir de una combinación de las esferas de acción y las cualidades de los personajes tales como el 
heroísmo. Es en las distintas maneras de unir estos elementos que surgen las distintas historias que leemos; pero es también de acuerdo al modo en que leemos esas historias, que aquellas uniones se vuelven más o menos visibles. "Escribir, es a menudo una nueva articulación y efectivamente una nueva formación que se extiende más allá de sus propios modos” (Williams 1980: 242). En este sentido, la escritura militante organiza el testimonio dentro de las presiones y las disputas políticas por las memorias del pasado. La escasa documentación oficial, los huecos en la memoria colectiva y los silencios de las víctimas fueron los grandes desafíos de los autores de los testimonios. Desde sus borrosos dominios iniciales, el género ha avanzado hacia una condición de prueba jurídica en los Juicios Civiles contra los represores.

En la memoria literaria, el testimonio ha desarrollado un espacio con marcas particulares; desde las representaciones literales hasta sus flexiones más ficcionales, el género ha desarrollado sus protocolos en torno a las ideas de memoria y transmisión y al tema del héroe en relación a sus personajes. Los acontecimientos se pueden contar de diferentes maneras sin alterar el orden cronológico en el que realmente sucedieron. La "dictadura" aparece en los testimonios como una historia susceptible de ser contada de manera distinta una y mil veces; los escritores del género postulan, al menos en el imaginario, la necesidad de convertir en victoria las derrotas de la lucha armada.

Libros como La Anunciación (2007) de María Negroni o las Violetas del paraíso. Memorias montoneras de Sergio Pollastri (2003), intervienen en el territorio de los trabajos narrativos de la memoria de un modo que hay que calificar de extraordinario o, si se quiere, raro. Ambos textos introducen la variable del género sexual como un elemento a contrapelo del relato heroico y del tono patriarcal de los testimonios romantizados de la violencia. Interrumpiendo el hilo de una primera persona, las novelas narran de manera fragmentaria, la experiencia de los jóvenes militantes del peronismo revolucionario de los años setenta. Pollastri apuesta a la organización narrativa de una serie de los recuerdos personales atravesados por citas de noticias de la prensa hegemónica de la época; el contrapunto de visones desmonta falsedades. Negroni inscribe la dimensión del género y el relato de una moral militante que organiza cuerpos y pasiones. (Daona, 2011) Ambos autores tienen como elemento común el recorte fragmentario de los procesos de transmisión de las experiencias personales. En ambos, la inclusión de una dimensión de la subjetividad habilita la imaginación de mundos futuros posibles (Jelin y Kaufman, 2006: 9) e introduce una quiebre en el triunfalismo autoritario y militarista de la prensa oficial de Montoneros. La lógica del detalle desmonta las codificaciones de esa "literatura de las virtudes" que caracteriza ciertas memorias narrativas de la militancia revolucionaria de los ' 70 . 


\section{Constelaciones del presente: los héroes y los relatos heroicos}

La escritura testimonial reciente, cuya narrativa más potente es quizás la de Laura Alcoba, abre el relato de la violencia política hacia las zonas canónicamente ocupadas por las representaciones de la subjetividad. Las historias de la dictadura y exilio se cuentan desde los espacios interiores de una sinrazón. En el espacio de lo privado se inscribe el exterminio masivo, la historia de cada uno de los sujetos y sus contingencias. Las épicas generacionales de la opción por la lucha armada devienen en historias de vida en clave menor. En las narrativas más recientes, el testigo se convierte en personaje y encuentra otras legitimidades para enunciar su relato. Si bien la autora no se desvincula del "familismo" los protocolos iniciales, su expresividad no está sólo potenciada por su condición de "hija" sino también por la poética del relato y por el campo intelectual que lo autoriza.

Las novelas testimoniales de Alcoba proponen la lectura de los cuentos revolucionarios dichos entre "viejos guerreros" (Davoine y Max Gaudilliére, 2011) que cuentan siempre lo mismo y los nuevos lectores que no pueden evitar escucharlos. La casa de los conejos (2008), es una novela fundacional de los nuevos modos de la narración testimonial. "La ficción se confunde con la autoficción en tanto la narradora, que se llama Laura, revisita lo que fueron sus vivencias en una casa operativa de Montoneros durante los años 1975 y 1976” (Daona 2015). En Los pasajeros del Anna C., los padres de "Laura", son los "revolucionarios errantes" (261). "Con esa pinta de disfrazados para un corso", "parecemos una troupe de circo" (250). Son los pasajeros de un barco decadente del presente, vacío de los lujos de otro tiempo.

La poética del fantasy (Jackson, 1986) fractura el realismo de los primeros textos con el extrañamiento de lo fantasmático sobre el pasado. La organización de una trama narrativa desde el escenario de un barco vacío para transportar a los actores de un proyecto colectivo, permite la emergencia de una literatura imaginativa sobre el pasado. Los nuevos relatos complejizan la figura del referente y sus certezas, se permiten ambigüedades sobre el pasado y sus personajes a la vez que exacerban las potencialidades de las metáforas. Cito como un ejemplo de las nuevas modulaciones Montoneros o la ballena blanca (2102) de Federico Lorenz.

La escritura de Lorenz vincula dos experiencias violentas: la acción revolucionaria de Montoneros y la guerra de Malvinas; la moneda de intercambio es la metáfora de la ballena blanca de Melville. El narrador cuenta su propia experiencia e historiza lo que hasta el momento no ha sido "alojado" en ningún relato; un ritual secreto, un testimonio con fuertes marcas de intimidad que no ha sido recibido por ningún discurso. Soldados que van a una guerra a contrapelo del tiempo. Lorenz se propone cruzar relatos que no eran permeables en otras épocas: la guerra como opción política y un encuentro paradojal entre dos derrotas. La revolución como un sueño eterno y la guerra de Malvinas (Nofal 2014: 121). Las 
figuraciones de ambos cuentos de guerra parten del presupuesto de inscribir un tiempo que no pasa y desorganiza el funcionamiento de las metáforas que convocan a la aventura de vivir una experiencia vital como un relato de aventuras. Las epopeyas cuentan historias de guerras y combates.

El uso de los testimonios orales y emergencia de un género escriturario particular se suman a las paradojas de la diversidad de los objetos literarios que buscan una inclusión en límites móviles. El límite del género está marcado por los usos políticos de la palabra testimonial. Pensar la guerra como un cuento invierte las narrativas sobre la firmeza del héroe de los relatos tradicionales. El héroe se convierte en un personaje discordante, identificable con una figura permanente y a la vez cambiante. Es también el cuerpo de la ballena y sus colonias de mejillones el que interviene en el curso de las cosas con sus propias marcas y altera el protocolo heroico del género, que en el sentido más literal del término construye una matriz ordenada de escrituras que autoriza y custodia con ciertas formalidades.

El héroe derrotado en términos de la configuración tradicional altera la serie lineal de los relatos y permite combinaciones más complejas. Los papeles fijos se transforman y se quiebran las reglas de la completitud, de la unidad y de la totalidad de la trama. Todo se sucede en la misma mesa de trabajo, como en el libro de Laura Alcoba, entre las armas y el dulce de leche. ${ }^{1}$ Juego de equívocos y de peligros, la dialéctica de la concordancia y de la discordancia permiten un giro desde la centralidad de la trama a la identidad del personaje.

En términos de Paul Ricoeur (1999: 224), este desplazamiento que se sucede en la poética permite imaginar un sentido y una identidad referida principalmente en el acto de lectura. La centralidad del personaje desplaza el protagonismo de la primera persona hacia una instancia de representación de la subjetividad a partir de configuraciones metafóricas. El héroe como personaje organiza los cuentos de la guerra en términos de asimetrías con lo real más allá de las formas canónicas del testimonio letrado (Nofal 2002) ${ }^{2}$ y desplaza los mandatos de veracidad a las configuraciones de la fantasía. "El primer narrador verdadero fue y seguirá siendo el narrador de cuentos” afirma Walter Benjamin (2008: 86) en

\footnotetext{
1 "Por el camino de vuelta, me detengo al borde de una u otra zanja de aguas servidas. Tengo un pequeño frasquito para encerrar renacuajos. Por fin vuelvo rápido a tomar la merienda. Hoy es el día en que se limpian las armas. Yo trato de encontrar un pequeño sitio limpio en la mesa atestada de hisopos y cepillos empapados en aceite. No quiero ensuciar mi rodaja de pan untada con dulce de leche" (La casa de los conejos 84).

${ }^{2}$ En La escritura testimonial en América Latina. Los imaginarios revolucionarios del Sur. 1970-1990 (2002) propongo leer los testimonios como un género particular con marcas de un realismo que se inscriben en la tradición del sistema literario. Desarrollo la hipótesis del carácter residual del testimonio desde la crítica literaria. Estos relatos forman parte de las representaciones simbólicas de la literatura en tanto "no sólo representan una realidad sino que intentan disputar un espacio de interpretación de la misma” (Nofal 2002: 19). Se trata de un género literario que rechaza las leyes de la representación artística y se imagina fiel reproductor de lo real, lo que lo acerca más a la crónica periodística que a la novela. Los testimonios canónicos son aquellos en los que tanto el informante como el entrevistador pertenecen a los circuitos letrados y se definen como intelectuales.
} 
Rossana Nofal. Configuraciones metafóricas en la narrativa...

su ensayo sobre la experiencia para dar cuenta de la guerra y sus efectos en los soldados. Las figuraciones de los cuentos de guerra no parten del presupuesto de decir la verdad, sino de decir lo que es inevitable callar, configurando nuevos imaginarios para contar la violencia política. Se trata de escrituras que tienen algún vínculo con cierta noción de belleza o de dimensión estética no siempre precisa. La nueva literatura testimonial reciente da cuenta de la experiencia de "de lo imposible o lo no razonable mediante la capacidad de cierta forma artística para poner en cuestión cualquier certidumbre" (Dalmaroni, 2004: $128)$.

\section{La guardarropía revolucionaria en los cuentos de guerra}

Las experiencias de la guerra jamás fueron desmentidas, afirma Benjamin (2008) ${ }^{3}$. A casi cuarenta años del golpe, el corpus testimonial argentino organiza nuevos relatos sobre las militancias y sus batallas. Las experiencias de la violencia, sus silencios y sus traumas se conjugan con la voluntad de sobrevivir para escribir la historia de lo sucedido. El género testimonial en Argentina tramitó de múltiples maneras los huecos simbólicos, los duelos y los silencios conspirativos de los sobrevivientes. La literatura testimonial ha dado cuenta de estas estrategias narrativas y de los usos legales de estos relatos al momento de juzgar a los genocidas en los tribunales civiles. Aunque una vez que los tribunales emitieron una sentencia, la literatura testimonial se liberó del mandato de veracidad.

Es difícil "desmentir" los cuentos de la guerra. A partir de los nuevos libretos del estado de derecho y de la acción eficaz de la justicia y sus reparaciones, la literatura testimonial se permite la configuración de una nueva agenda vinculada a una ficción sobre las memorias en conflicto y la organización de su poética. Los autores del género no tienen el mandato de hablar por delegación de las víctimas y sus familiares. "Cuando alguien realiza un viaje, puede contar algo", reza el dicho popular referido por Benjamin (2008: 61) para representar al narrador como alguien que llega desde muy lejos.

“Mi viaje comenzó en alguna parte detrás de mi nariz”. Tomo la idea del viaje como una metáfora que organiza los relatos testimoniales de Laura Alcoba. El viaje y una lengua otra, el francés, se inscriben siempre en el ejercicio memorioso de reconstruir su biografía en El azul de las abejas (2015). "Un día,

\footnotetext{
3 “Con la Guerra Mundial comenzó a hacerse evidente un proceso que desde entonces no ha llegado a detenerse. ¿o se advirtió que la gente volvía enmudecida del campo de batalla? No más rica, sino más pobre en experiencias comunicables. Lo que diez años más tarde se derramó en la marea de los libros de guerra, era todo lo contrario de una experiencia que se transmite de boca en boca. Y eso no era extraño. Pues jamás fueron desmentidas más profundamente las experiencias como (lo fueron) las estratégicas por la guerra de trinchera, las económicas por la inflación, las contemporáneas por la batalla mecánica, las éticas por los detentadores del poder. Una generación que todavía había ido a la escuela en el carro de sangre, se encontró a la intemperie, en un paisaje en que nada quedó inalterado salvo las nubes, y bajo ellas, en un campo de fuerza de torrentes devastadores y de explosiones, el ínfimo y quebradizo cuerpo humano" (Benjamin 2008: 60-61).
} 
por fin, me reencontré con mamá en Francia. Sólo que no fui a vivir a París, como me había dicho tantas veces, sino cerca" (16). El trabajo con la novela Los pasajeros del Anna C. (2012) me permite incorporar un concepto clave al momento de dar cuenta de las configuraciones metafóricas de la nueva narrativa testimonial: la "guardarropía revolucionaria" $"$. Este constructo hereda los presupuestos de Ángel Rama (1985) cuando define la democratización modernizadora en América Latina como una acción política capaz de revisitar la Historia como una visita a la guardarropía del teatro. En La casa de los conejos, escrita "desde la altura de la niña que fui” (12), las marcas de una guardarropía se inscriben en el pelo naranja de la mamá y el saco con su verdadero nombre que Laura lleva a la escuela. (Nofal, 2014(b): 281) En su última novela, Alcoba suma a la guardarropía la metáfora del color azul.

La productividad del concepto de guardarropía resignifica la lectura del género testimonial iniciada con un giro desde la centralidad de la trama en los testimonios canónicos a la centralidad del personaje en las poéticas de la memoria. Este nuevo giro sobre la crítica literaria permite generar nuevas hipótesis interpretativas sobre la legitimidad de la palabra en el testimonio. Vestuario o disfraz, trapero o poeta, como afirma Benjamin (1991:31), “a ambos les concierne la escoria; el paso del poeta que vaga con su botín de rimas; tiene también que ser el paso del trapero, que en todo momento se detiene en su camino para rebuscar en la basura con que tropieza". ${ }^{5}$ Los personajes de Alcoba escriben la experiencia concentracionaria como poetas y como traperos. El padre busca metáforas sobre la libertad en las cartas que intercambia con su hija a propósito de la discusión sobre el color preferido de las abejas. La madre busca ropas usadas en las bolsas de la caridad.

Una noche mi mamá irrumpió en mi cuarto cargando sus trofeos: polleras y camisas para ella y Amalia, más una bolsa que una señora de Cáritas, que ya nos conocía muy bien, había apartado cuidadosamente para mí. Tuve la impresión de que la ropa de esa bolsa provenía del mismo armario que mi madre había revuelto dos meses atrás, cuando todavía estábamos en el corazón del invierno (Alcoba, 2014: 107).

\footnotetext{
4 Tomo el concepto del libro de Ángel Rama, Las máscaras democráticas del modernismo (1985) Capítulo III ("La guardarropía histórica de la sociedad burguesa"), si bien no lo desarrolla en su totalidad, llama la atención sobre el vestuario de Rubén Darío y su capa en la consolidación del modernismo. En este capítulo Rama se refiere a las lecturas de la Revolución Francesa que hacen Marx y Nietzsche. Traza puntos de contactos y líneas de fuga y destaca el acontecimiento disfrazado que había en ellas. Casi toda la cultura moderna cumplía una función enmascaradora, señala, "debido a que intentaba suplantar el texto del pasado con la interrupción moderna como un modo de hacer suyo el mensaje que ya no le pertenecía y que necesitaba adecuar a sus impulsos, a sus secretos deseos, a su ideología”. (82)

5 "Los traperos aparecieron en mayor número en las ciudades desde que los nuevos procedimientos industriales dieron a los desperdicios un cierto valor. Trabajaban para intermediarios y representaban una especie de industria casera que estaba en la calle. El trapero fascinó a su época. (31) "Naturalmente el trapero no cuenta en la bohemia. Pero todos los que formaban parte de ésta, desde el literato hasta el conspirador profesional, podían reencontrar en el trapero algo de sí mismos. Todos estaban, en una protesta más o menos sorda contra la sociedad, ante un mañana más o menos precario. A su hora podía el trapero sentir con aquellos que daban tirones a las cáscaras fundamentales de la sociedad. En su sueño no está a solas. Le acompañan camaradas; también en torno a ellos hay aroma de barriletes y también ellos han encanecido peleando” (32).
} 
En Los pasajeros del Anna $C$, las ropas de los personajes constituyen un complejo de símbolos que nos señalan las direcciones para encontrar un ícono que articula la interpretación de estos acontecimientos: la ropa, como la revolución, le queda grande a nuestros protagonistas. En Cuba esperaban militantes y activistas aguerridos; sólo llega una "banda de chiquilines". Entre el cuartito azul y la cocina amarilla comienza el desplazamiento de las identidades prefiguradas y las identidades reales. “Ninguno de ellos se reconocía en la descripción”. El yo de Laura autora de su biografía insiste una y otra vez en la edad de su madre: veinte años. La puesta en escena de ese grupo guerrillero ficticio está organizada por un loco que luego se volverá asceta.

Los nuevos personajes están disfrazados o con ropas fuera de su tiempo: como soldados en harapos en la obra de Lorenz, con buzos de lana con rayas de muchos colores en las novelas de Laura Alcoba. Las máscaras cambiantes son constitutivas de la trama testimonial del pasado. Mediante ellas la persona del relato testimonial deviene en el personaje de la narratología revolucionaria. Se deja de ser "uno mismo" para ser la máscara que se ha construido. Quien no es capaz de hacerlo puede recurrir a la guardarropía de la historia revolucionaria. La estrategia narrativa de Alcoba supone una inscripción subjetiva del relato histórico organizada a partir del semblante de los personajes, un juego múltiple y complejo entre el ser y el parecer y una puesta particular de vestuario que convierte a la revolución en un acontecimiento que puede narrarse.

La utilidad inicial de la ropa se pierde y se convierte en un incómodo guardarropa en donde resulta difícil alojarse. La ropa se convierte en disfraz, ropa de otros, extraña, inverosímil, desplazada del cuerpo y del espacio. Envejecida, incluso antes de usarse. El libro puede leerse como la crónica ordenada de un viaje hacia la revolución y su vestuario. En el espacio subjetivo que se inscriben las fechas del comienzo y del final de un entrenamiento en otro espacio entre setiembre de 1966 y mediados de 1968 para volver a entrar en una revolución propia en el suelo nacional, casi a punto de comenzar, al menos, imaginariamente. El relato se organiza alrededor de las máscaras que habían elegido entonces y la verdad de quiénes eran; en el inicio se marca el cambio de ropas: "Soledad recuerda que no bien entraron al departamento, Juan Carlos les pidió que entregaran sus ropas a aquellos hombres; a cambio les dieron ropas cubanas" (58) "Les dieron a cada uno su equipo: uniformes verde oliva, gorras de visera y botas soviéticas. Sin olvidar las armas, por supuesto” (84).

Entrenamiento guerrillero y principio de nocturnidad son los dos conceptos que resumen la experiencia cubana que se relata en clave teatral. Con la lógica de la desmesura se escribe la historia de un viaje exagerado con ropas ajenas y relatos fragmentados y dispersos. El objetivo de esta operación es doble: por un lado permite acentuar las operaciones figurativas de un pasado equívoco imaginado más que recordado en el que el chaquetón más pequeño quedaba grande en los cuerpos de los protagonistas. Por el otro lado, la narrativa de Alcoba hiperboliza el aislamiento de las operaciones políticas de sus 
padres en el relato de acciones en las que siempre se siente la extrañeza de un vestuario fuera de lugar: vestir ropas de otros cuerpos, vivir la vida de otros, perder la identidad propia y recuperarla en otra orilla.

En El azul de las abejas, Alcoba visita una caja con "recuerdos persistentes aunque muchas veces confusos" (125). Es una novela sobre cartas desaparecidas ${ }^{6}$ y una colección incompleta de fotografías. "Las "e" mudas me fascinan desde siempre" (70). Aprender a leer y escribir en francés y completar la colección de cinco fotos son los movimientos internos de una trama que se organiza desde una reflexión sobre el lenguaje "En esa quinta imagen, que completará y cerrará su colección, él quiere que yo aparezca con mi madre" (44).

El coleccionista, dice Walter Benjamin, (2011) tiene en su pasión una varita mágica que le hace descubrir fuentes nuevas. ${ }^{7}$ Alcoba se convierte en una paseante de sus propios recuerdos; no busca un sentido, o la verdad de los hechos. Los fragmentos que se coleccionen desarticulan las totalidades y los protocolos heroicos del género del género testimonial canónico, generalmente vinculados a las figuras de los justicieros, querellantes en juicios inexistentes. La palabra literal del testimonio se vuelve palabra poética y ambivalente. Con la organización narrativa de los elementos de referidos al color de los objetos, el testimonio se convierte en una imagen o en constelaciones de imágenes.

Las visitas con su abuela a su padre en la Cárcel de Devoto inscriben la zona más literal del relato en todas las obras de Alcoba. Se reitera la narración de sus cuerpos violentados por las guardias y los controles; en las zonas poéticas de las memorias, el recuerdo acontece en escrituras contrapuestas. La escritura desaparecida es la escritura que la narradora repone en el presente con imágenes del pasado. Pero el libro que busca no habla de flores ni del color azul. La interpretación está siempre a contrapelo de la prefiguración. Nada es lo que parece. La narradora asedia muchas veces la traducción del libro, muchas cosas quedan en sombras, equívocos o malentendidos.

Tan pronto como la leí me dije que esa sola frase justificaba tanta, tanta pena: "Un manto de lodo cubría aún toda la tierra; pero ya, aquí y allí, asomaban pequeñas flores azules” (123) Algo que me gusta mucho en las cartas que nos escribimos mi papá y yo, es que a veces logro olvidar dónde está él, y me pondo a hablar de las abejas y de los colores a los que son sensibles; adoro ese tema. ¿A vos qué te parece? ¿Por qué prefieren el azul? (Alcoba, 2014: 45).

En un mundo de la narrativa testimonial que produce ángeles y monstruos las alegorías de Alcoba imponen nuevas configuraciones. La travesía en Los pasajeros del Anna C. se clausura con la imposición

\footnotetext{
6 "Mis cartas desaparecieron pero yo conservo las suyas" (125).

7 "Basta con recordar la importancia que para todo coleccionista tiene no sólo el objeto, sino también todo su pasado, al que pertenecen en la misma medida tanto su origen y calificación objetiva, como los detalles de su historia aparentemente externa: su anterior propietario, su precio de adquisición, su valor, etc. (225) Una especie de desorden productivo es el canon de la memoria involuntaria y también del coleccionista" (229).
} 
de un vestuario revolucionario que habla por sí mismo y cuenta su cuento uniformado sin la contradicción y las paradojas de la moda. "Porque en las grandes ciudades de América del Sur, al igual que en París, las chicas usaban entonces minifaldas cortísimas y blusas floreadas y chalecos de cuero negros. Como Brigitte Bardot” (12) Los personajes principales se desdibujan como modelos ideales de héroes revolucionarios cuando el romance cede a la tentación de novelar de su autora.

Teatro, escenario y personajes: el vestuario configura el acontecimiento que el espectador vive en una noche. En un barco casi vacío, ocupan, casi como fantasmas del pasado, la primera clase. Cruzan el mar, desplazados de su tiempo y de su moda. Las ropas y las revoluciones rusa y cubana parecen ser diseños de temporadas anteriores. La minifalda se reemplaza con el hábito: ocultamiento, discreción y clandestinidad. Las valijas de la historia guardan entonces tanto lo descubierto como lo inventado, ambas instancias igualmente ajenas al cuento heroico y romantizado de una revolución y su destino. La travesía de El azul de las abejas no concluye, tampoco se llega a París sino cerca. Pero se alterna los vestuarios siempre a contrapelo con variables extrañas.

Josefina Ludmer (1977:148) define "cuento" como las matrices productoras de relatos que pueden ser diversas e indefinidas; “están entrelazadas y forman nudos; quizás los únicos rasgos que las distinguen sean su impersonalidad (parecen emitidas por nadie) y su carácter anacrónico. Son, en síntesis, figuras abstractas, tejidas de relaciones simbólicas, que en cada caso se actualizan con tiempos, modos, pronombres, sintagmas y situaciones narrativas determinadas (...) Las matrices productoras del texto no coinciden con lo dado ni se captan de un modo inmediato: hay que reconstruirlas y asignarles funciones. Pero, el texto, no esconde nada: todo es legible, todo está allí, en el espacio aparentemente lineal de la escritura. La matriz no ocupa una zona "profunda"; ni siquiera se sitúa en una región “mental” previa (idea, sentimiento, intención) que preexistiría como causa del texto; no es tampoco su origen, su centro, ni la clave-llave para descifrarlo”. Ludmer los define en términos de relatos de carácter fragmentario, que se reiteran como partes de historias mayores.

La experiencia que se trasmite de boca en boca, dice Walter Benjamin, es la de los narradores. Cuando alguien realiza un viaje, puede contar algo y el detalle del relato subjetivo de la experiencia puede quebrar la repetición ritualizada del sufrimiento que caracteriza al testimonio canónico ${ }^{8}$. Se hace necesario, señala Susana Kaufman (2006: 68), revisar los silenciamientos en los relatos memoriosos para comprender si llevan a la idealización del imaginario emancipatorio de los setenta, si entran en

\footnotetext{
${ }^{8}$ Tomo el concepto de "detalle" de Walter Benjamin para organizar la caja de herramientas metodológicas para leer la narrativa testimonial y sus poéticas. "Haciendo primeros planos de nuestro inventario, subrayando detalles escondidos en nuestros enseres más corrientes, explorando entornos triviales bajo la guía genial del objetivo, el cine aumenta por un lado los atisbos en el curso irresistible por el que se rige nuestra existencia, pero por otro lado nos asegura un ámbito de acción insospechado, enorme (Benjamin 1989: 47).
} 
Rossana Nofal. Configuraciones metafóricas en la narrativa...

pactos de silencio para omitir zonas de dolor o si evitan la confrontación con los valores, los sentidos ideológicos y los modos de la política de aquellos años.

El narrador organiza las metáforas transmitir, en clave poética, las experiencias de las mochilas enmudecidas de Benjamin. La lógica del "cuento" y sus personajes permite repensar la figura de los "emprendedores de memoria" y reemplazarla por la de los contadores de cuentos. Elizabeth Jelin (2002), los definía como activistas activistas de la memoria. "En el planteo de la acción de los ‘emprendedores de la memoria' está implícito el uso político y público que se hace de la memoria”, su papel fue central en la dinámica de los conflictos alrededor de la memoria pública (51). A la luz de los nuevos marcos de interpretación y de las instancias jurídicas del castigo a los culpables, la tramitación política de la memoria incluye modulaciones subjetivas e historias particulares. Más allá de las consignas iniciales de los movimientos de Derechos Humanos, la transmisión de las memorias traumáticas integra agendas educativas y es también una de las acciones de los cuentacuentos y sus alegorías para contar la verdad.

\section{Los trabajos de la memoria y sus temporalidades}

En un artículo del año 2004, Elizabeth Jelin analiza el surgimiento de un nuevo campo de preocupaciones en las ciencias sociales latinoamericanas: los derechos humanos, las memorias de la represión y la violencia política. En este desarrollo narra los antecedentes conceptuales y las condiciones históricas que dieron lugar al surgimiento de este campo interdisciplinario en el que se inscriben las marcas propias de su biografía intelectual. Con un rol protagónico en los hacedores, Jelin siempre convocó a redefinir las fronteras entre los espacios públicos y los privados a la luz de la dimensión de la vida cotidiana. Las tensiones entre la urgencia de rememorar y recordar los hechos, los huecos traumáticos y las heridas abiertas constituyen el objeto de investigación, pero también su obstáculo más grande: la paradoja de decir con palabras públicas lo indecible de los tormentos (Jelin, 2002). Igualmente Jelin pensó, como un mandato epistemológico, la necesidad "de que la investigación siempre historice las memorias” (2004: 103). Sumó a sus presupuestos la compleja definición de las temporalidades de Koselleck (1993: 335), entendidas como la vinculación del tiempo histórico con las experiencias de los hombres que viven y actúan en ese escenario. Las experiencias nunca se inscriben como discursos lineales. Esta es una de las advertencias de Jelin: escuchar los matices de cada relato. Las experiencias y las temporalidades se superponen, se entremezclan y se articulan siempre desde el conflicto.

"Hace unos meses apenas... o una eternidad, ya no lo sé" (Alcoba, 2014: 15). La lectura de las múltiples disputas políticas por la legitimidad de la palabra memoriosa y sus sujetos implica activar 
memorias subterráneas, zonas grises de traiciones, derrotas y olvidos. Implica también el ejercicio de habilitar nuevas interpretaciones de las mismas escrituras e iluminan los silencios deliberados en los textos leídos una y mil veces. Leer al revés implica leer la desarticulación del discurso heroico en las memorias de militancias. En este sentido, el desarrollo del concepto de "cuentos de guerra" entendidos como partículas narrativas inscriptas en relatos complejos ubica a la escritura de Laura Alcoba no sólo en el espacio de la experiencia sino también en el "horizonte de expectativa, constructo que hace referencia a una temporalidad futura para la lectura de su propia obra "nuevas esperanzas o desengaños, nuevas expectativas, abren brechas y repercuten en ellas" (Koselleck, 341). La escritora vincula lenguaje con tiempo y complejiza el relato de la memoria con una idea de pasado en otro registro. "Porque yo hablaba cada vez mejor, claro, y eran cada día menos las palabras que verdaderamente no entendía, pero el problema -y yo lo sabía bien- era que todo pasaba en dos tiempos: pensaba en castellano y traducía mentalmente las palabras, y sólo después abría la boca” (2014: 118).

En el nuevo prólogo a Los trabajos de la memoria (2012), Elizabeth Jelin señala que si se realiza un estudio del devenir temporal de las diversas interpretaciones y sentidos que adquiere el pasado, se hace evidente que las memorias tienen una temporalidad propia que no puede homologarse a la linealidad del paso del tiempo. A esta no linealidad, Jelin la entiende a partir de la existencia de los "emprendedores de memorias" que no dejan que ese pasado se olvide, pero también por la presencia de las nuevas generaciones y sus preguntas novedosas en relación al pasado. "Quizás -dice Jelin- lo específico de la memoria es que siempre está abierta, sujeta siempre a debates sin líneas finales, constantemente en procesos de revisión" (2012: 17) Alcoba reescribe su historia con letra propia. La demanda de una voz subalternizada de los relatos iniciales se convierte en una palabra poética a contrapelo ${ }^{9}$. Constelación de imágenes y colección de fragmentos. La memoria acontece desarticulada, como un caleidoscopio que en su silencio reclama nuevas lecturas más allá de los formatos protocolares del género.

\section{Coda: lo innegable de la realidad de la guerra}

La posibilidad de leer la idea de guerra como un cuento que transmiten los cuenteros y que permanece inmutable en los relatos habilita las figuras de las memorias y sus poéticas. Las nuevas metáforas de la memoria, sus ballenas blancas, su guardarropía y sus traperos se desprenden de las narrativas tomadas de los testimonios iniciales de los sobrevivientes y sus familias. Los nuevos autores,

\footnotetext{
9 “Jamás se da un documento de cultura que no sea a la vez de la barbarie. E igual que él mismo no está libre de barbarie, tampoco lo está el proceso de transmisión en el que pasa de uno a otro. Por eso el materialismo histórico se distancia de él en la medida de lo posible. Considera cometido suyo pasarle a la historia el cepillo a contrapelo" (Benjamin 1989: 182).
} 
fundamentalmente los hijos de los militantes, reconfiguran un campo literario que exige una caja de herramientas específicas para leer las memorias políticas en clave de literatura de fantasía alejada del realismo socialista de los primeros relatos.

Junto a las categorías convencionales de la narratología tomadas de la filosofía de Paul Ricoeur (1999) y su relectura sociológica en clave de un campo específico de objetos que inaugura Elizabeth Jelin (2002-2012) para pensar el familismo de las disputas políticas por las memorias en conflicto, sumo las categorías de la crítica literaria de Josefina Ludmer (1977) para leer los testimonios en términos de "cuentos de guerra" con sus "personajes", sus estereotipos y sus autofiguraciones "heroicas" que se transmiten generacionalmente por los contadores de cuentos.

Frente a la sumisión a la realidad de los relatos fijados por la transcripción literal de los entrevistados y sus dichos, las poéticas de la memoria toman los riesgos de la inversión de una trama que puede ser rara, insólita, abreviada y hasta falsificada. Los cuentos de un narrador pueden entenderse como fragmentos dentro de un relato mayor. Las partículas de sentidos múltiples pueden migrar a distintas geografías y modificar las cronologías hasta el punto de suprimirlas. Los cuentos de guerra y los cuenteros de la revolución organizan constelaciones metafóricas sobre el pasado: el color azul, la figura del trapero, la guardarropía, el barco de los locos errantes, la ballena blanca y el coleccionista. Es necesario, entonces, un modelo móvil para leer los mismos libros, con la suficiente plasticidad para catalogar el espesor del sistema; un aparato de lectura para explicar imágenes y vestuarios de ropavejeros para volver audibles los conflictos, las tensiones, los ocultamientos, las desapariciones, sus escrituras y sus urdimbres. 


\section{Corpus}

Alcoba, Laura (2008). La casa de los conejos. Buenos Aires: Edhasa.

Alcoba, Laura (2012). Los pasajeros del Anna C. Buenos Aires: Edhasa.

Alcoba, Laura (2014). El azul de las abejas. Buenos Aires: Edhasa.

Bonasso, Miguel (1994). Recuerdos de la muerte. Buenos Aires: Planeta.

Lorenz, Federico (2012). Montoneros o la ballena blanca. Tusquets: Buenos Aires.

Negroni, María (2007). La Anunciación. Buenos Aires: Seix Barral.

Pollastri, Sergio (2003). Violetas del paraíso. Memorias montoneras. Buenos Aires: El cielo por asalto.

\section{Bibliografía}

Benjamin, Walter (1989). Discursos interrumpidos I. Madrid: Taurus.

Benjamin, Walter (1991). Poesía y capitalismo. Iluminaciones II. Madrid: Taurus.

Benjamin, Walter (2008). Elnarrador. Santiago de Chile: Metales pesados.

Benjamin, Walter (2011). El libro de los pasajes. Madrid: Akal.

Dalmaroni, Miguel (2004). La palabra justa. Literatura, crítica y memoria en la Argentina. 1960-2002. Santiago de Chile: RIL- Melusina Editorial.

Daona, Victoria. “Acerca de La Anunciación de María Negroni y la escritura fragmentaria de la violencia política en la Argentina de los años '70". Stockholm Review of Latin American Studies. 7 (2011): 87-98.

Daona, Victoria. "Princesas, combatientes y pilotos. Estéticas de filiación en las narrativas de los/as hijos/as de desaparecidos/as en Argentina”. Telar. Revista del Instituto de Estudios Latinoamericanos de la Facultad de Filosofía y Letras de la U.N.T13-14 (2015):166-186.

Davoine, Francoise y Gaudilliére, Jean-Max (2011). Historia y trauma. La locura de las guerras. Fondo de Cultura Económica: Buenos Aires.

Jackson, Rosemary (1986). Fantasy. Literatura y subversión. Buenos Aires: Catálogos.

Jelin, Elizabeth (2002). Los trabajos de la memoria. Madrid: Siglo XXI.

Jelin, Elizabeth y Kaufman, Susana (2006). Subjetividad y memoria. Buenos Aires: Siglo XXI.

Jelin, Elizabeth (2012). Los trabajos de la memoria. Lima: Instituto de Estudios peruanos. 
Jelin, Elizabeth. "Los derechos humanos y la memoria de la violencia política y la represión: La construcción de un campo nuevo en las ciencias sociales" Estudios Sociales, Revista Universitaria Semestral, Año XIV, Santa Fe: Universidad Nacional del Litoral 27 (2004): 91-113.

Koselleck, Reinhart (1993). Futuro pasado. Para una semántica de los tiempos históricos. Barcelona: Paidós.

Ludmer, Josefina (1977). Onetti: Los procesos de construcción del relato. Sudamericana: Buenos Aires.

Nofal, Rossana (2002). La escritura testimonial en América latina. Imaginarios revolucionarios del sur. 1970-1990. Tucumán: IIELA, Facultad de Filosofía y Letras: Universidad Nacional de Tucumán.

Nofal, Rossana (2009). "Literatura y testimonio". La investigación literaria. Problemas iniciales de una práctica. Santa Fe. Secretaría de Extensión, Universidad Nacional del Litoral:141-158.

Nofal, Rossana (2014) (a). "Las nuevas configuraciones del relato testimonial. La escritura de Federico Lorenz: de ballenas, locura y los mares del sur” en: Anna Forné Strategies autoficcionelles/ Estrategias autoficcionales, Peter Lang, Frankfurt: Alemania.

Nofal, Rossana. (b): "La guardarropía revolucionaria en la escritura de Laura Alcoba” en El taco en la brea, CEDINTEL, Centro de Investigaciones Teórico- Literarias, Facultad de Filosofía y Humanidades, UNL. 1 (2014): 277-287.

Rama, Ángel (1985). Las máscaras democráticas del modernismo. Montevideo: Fundación Ángel Rama. Ricoeur, Paul (1999). Historia y Narratividad. Barcelona: Paidós.

Williams, Raymond (1980). Marxismo y literatura. Barcelona: Península. 